\title{
LAS CONSTRUCCIONES DE LAS IMÁGENES DE SALTA. ARTICULACIONES ENTRE NOTICIAS Y FICCIONES CINEMATOGRÁFICAS
}

\author{
The constructions of the images of Salta. Articulations between news and cinematographic fictions
}

\section{Víctor Arancibia $^{1}$ y María Natalia Saavedra $^{2}$}

\begin{abstract}
Resumen
El presente artículo tiene como objetivo analizar cómo es que se construyen diversas imágenes de la ciudad de Salta, a partir de la indagación de noticias, como producciones televisivas, y de ficciones cinematográficas. Es decir, modalidades con que se representa visualmente a la ciudad tanto en clave informativa como ficcional. La metodología es cualitativa, emplea la teoría de las Representaciones sociales, la Semiótica audiovisual, los aportes provenientes de la Socio-semiótica, además del estudio de las imágenes y de la construcción de identidades locales. Se toma como corpus de análisis las producciones ficcionales de Alejandro Arroz Luz de invierno e Historias de las orillas y tres piezas informativas audiovisuales que se relevaron de canales televisivos locales y que referencian sobre todo el barrio denominado 'Gauchito Gil', perteneciente a la zona sudeste de la ciudad de Salta. Se espera poder construir una mirada que atraviese formatos audiovisuales diversos y que funcionen como estrategias metodológicas para abordar la topicalización de las ciudades en las producciones audiovisuales en sus diferentes formatos. El trabajo pretende así colaborar con los estudios sobre ciudad, modalidades de representación en el campo audiovisual y las formas en que las memorias se construyen y se reentraman en los procesos identitarios locales atendiendo a dos modalidades de construcción diferenciados, dando cuenta del espesor temporal de las representaciones que se ponen 'en pantalla'. De esta manera, se tratará de caracterizar los modos de la confrontación distributiva simbólica sobre los sentidos de la ciudad de Salta.
\end{abstract}

<audiovisualidades $><$ imágenes de ciudad $><$ representaciones sociales $><$ memorias $>$

\begin{abstract}
The objective of this article is to analyze the manner in which different images of the city of Salta are constructed, based on the investigation of news, such as television productions, and cinematographic fictions. That is, modalities with which the city is visually represented both informatively and fictionally. The methodology is qualitative: we resort to the theory of social representations, the audiovisual semiotics, the contributions based on Socio-semiotics, in addition to the study of the images and the construction of local identities. The fictional productions of Alejandro Arroz Luz de Invierno and Historias de las Orillas are taken together with three audiovisual informative pieces as a corpus of analysis. Such corpus then is relieved from local television channels and refer to the neighborhood known as 'Gauchito Gil', located in the southeast area of the city of Salta. We expect to build a perspective that combines diverse audiovisual formats and that could work as a methodological strategy to address the construction of topics related to cities in audiovisual productions in their different formats. The work thus seeks to collaborate with studies on the city, modalities of representation in the audiovisual field, and the ways in which the memories are constructed and embedded within the local identity processes attending to two different construction modalities, manifesting the "wide temporal range" of the representations that are shown 'on screen'. In this regard, we will try to characterize the modes of symbolic distributive confrontation about the senses of the city of Salta.
\end{abstract}

<Audiovisuals $><$ City images $><$ Social representations $><$ Memories $>$

Recibido: 25/10/2017 //Aceptado: 10/01/2018

\footnotetext{
${ }^{1}$ Doctor en Comunicación por la Facultad de Periodismo y Comunicación Social de la Universidad Nacional de La Plata. Profesor Adjunto Regular con dedicación exclusiva, Universidad Nacional de Salta. varancia64@ gmail.com

${ }^{2}$ Licenciada en Ciencias de la Comunicación por la Universidad de Salta. Becaria Interna Doctoral por el CONICET Doctoranda en Comunicación Social en la Facultad de Periodismo y Comunicación Social de la Universidad Nacional de La Plata. Auxiliar Docente de Primera Categoría. Universidad Nacional de Salta. natali1409@hotmail.com.
} 
Siempre, ante la imagen, estamos ante el tiempo. Como el pobre ignorante del relato de Kafka, estamos ante la imagen como 'Ante la ley': como ante un marco de una puerta abierta. Ella no nos oculta nada, bastaría con entrar, su luz casi nos ciega, nos controla. Su misma apertura -y no menciono al guardia- nos detiene: mirarla es desearla, es esperar, es estar ante el tiempo. Pero ¿qué clase de tiempo? ¿De qué plasticidades y de qué fracturas, de qué ritmos y de qué golpes de tiempo puede tratarse en esta apertura de la imagen?

George Didi-Huberman

\section{Introducción}

La producción audiovisual salteña de los últimos quince años ha tratado de construir una representación acerca de los espacios urbanos de Salta como turística y tradicional, por una parte, y, por otra, una batería de representaciones que tratan de alejarse de ese paradigma. La primera imagen, en general, ha respondido a los discursos hegemónicos sobre una ciudad que responde a un paradigma que da cuenta de las historias oficiales sobre el lugar y que trata de reafirmar los relatos propios de la 'salteñidad' (Cebrelli y Arancibia, 2005). Sin embargo, como todas las ciudades latinoamericanas, la heterogeneidad es constitutiva más allá de las representaciones cristalizadas que se proponen imponer acerca de cada una de ellas. Dicha representación, la que trata de obturar la imagen monolítica de la ciudad, se ve interpelada por la aparición de producciones cinematográficas que tratan de posicionarse desde un lugar diferente como es el caso de la de realizadores como es Alejandro Arroz, tanto en su producción cinematográfica como en Luz de invierno o en su producción de series para televisión como el caso de Historias de las orillas.

La pregunta es cómo estas imágenes tienen vinculación con la producción de piezas informativas que circulan por los telediarios locales, que funcionan para un consumo 'interno' de imágenes y que referencian las zonas periféricas de la ciudad que forman otro corpus de imágenes que impactan en los modos de percibir las características de la ciudad. El objetivo principal tiene que ver entonces con analizar cómo es que se construyen diversas imágenes de la ciudad de Salta, a partir de la indagación de producciones televisivas (noticias) y de ficciones cinematográficas. Es decir que se trata de indagar acerca de las estrategias posiblemente coincidentes las producciones ficcionales y las informativas que circulan por los espacios audiovisuales provinciales. La metodología es cualitativa, emplea la teoría de las Representaciones sociales (Hall, 2003 y 2010; Reguillo, 2008; Rodríguez, 2011: Cebrelli y Rodríguez, 2013; Cebrelli y Arancibia, 2005, 2008, 2011), la Semiótica audiovisual, los aportes provenientes de la Socio-semiótica, además del estudio de las imágenes y de la construcción de identidades locales.

Para ello se toma como corpus de análisis el film dirigido por Arroz estrenado en el año 2007, la serie de ficción que se produjo en el 2012, y tres piezas informativas en formato audiovisual que se relevaron de canales televisivos como Canal 4 de Salta y La gaceta en su versión digital, que referencian -sobre todo, 
tomándolo como un caso testigo- el barrio denominado 'Gauchito Gil'. El mismo forma parte de la zona sudeste de ciudad de Salta, se inició en el año 2009 cuando una serie de familias se asienta de manera ilegal en terrenos fiscales, no aptos para el hábitat. Sólo contaban con plásticos, maderas y chapas, que improvisaban como paredes, techos y pisos. No contaban con condiciones mínimas de vida, ni con los servicios o instituciones necesarios, por lo cual debieron acudir a autoridades de gobierno, quienes nunca solucionaron sus necesidades. En definitiva, las problemáticas recurrentes tienen que ver con la pobreza extrema, la contaminación, la delincuencia, entre otros factores que se han constituido como el contexto en el cual el 'Gauchito Gil' se inició y en el cual desarrolló su proceso de transformación de asentamiento a barrio en vías de organización.

La idea de la confrontación entre las formas de representar el margen es tratar de encontrar los elementos comunes y las difracciones entre las imágenes televisivas y las cinematográficas, entre la ficción y la información y entre las lógicas y los sistemas de representación que se ponen en juego (Cebrelli y Arancibia, 2005, 2008, 2012, 2017). Pero fundamentalmente se busca encontrar cuáles son los puntos en común entre las formas de representación de los habitantes de las zonas 'marginales' de la ciudad y que suelen ser invisibilizados por las representaciones más consolidadas (Cebrelli y Arancibia, 2017; Saavedra, 2015).

Las representaciones de los grupos humanos en los espacios urbanos contemporáneos, cómo plantea George Didi-Huberman (2014), están condenados a desaparecer ya sea por la lógica de la subexposición que los condena a la invisibilización o por la lógica de la sobreexposición que lleva a que la reiteración estereotipada produzca representaciones cristalizadas y las identidades diferenciadas no puedan percibirse. En ese sentido las formas de representación que se produce en los telediarios muchas veces retoman las formas más cristalizadas de representación y las ‘traducen' a un lenguaje que permite la visibilización y el reconocimiento rápido por parte de la recepción, impactando fuertemente en los imaginarios circulantes. Al mismo tiempo, la producción artística logra romper visualmente la construcción hegemónica mientras que otras, mayoritariamente la de los telediarios locales, sólo pone en imagen una representación con un espesor histórico que se hunde en la memoria local (Cebrelli y Arancibia, 2005, 2017).

En ese sentido, es clave encontrar las formas en que las memorias locales se van transformando y anclando en las imágenes de manera de lograr una pervivencia importante en la memoria visual de una comunidad. A la vez, las memorias de las formas de representar la marginalidad también se entraman en los discursos audiovisuales tanto cinematográficos como televisivos. En esa línea es que se trata de indagar en las formas de las retóricas propias de representar un sector de la sociedad y de sus recorridos tratando de aportar a la construcción de un repertorio de estrategias necesarias para considerar los estudios locales. Sobre todo, teniendo en cuenta que los lenguajes visuales, los sonoros, los verbales van construyendo un entramado de formatos que construyen modos de representación diferenciados.

Por ello, el trabajo se propone, también, rastrear las modalidades con que se mapea la ciudad tanto en clave ficcional como informativa estableciendo los puentes desde una perspectiva retórica más que genérica. En ese sentido, se trata de ver cómo interactúan las representaciones circulantes en la construcción de los 
imaginarios urbanos como lo señala Armando Silva (2012). Cada uno de los registros trabajados se analizarán desde el concepto de índices identitarios (Arancibia: 2015) entendidos como las operatorias audiovisuales mediante las cuales se buscan activar los procesos de identificación entre destinatarios e imágenes producidas audiovisualmente en la trama de las construcciones identitarias (Hall, 2003, 2010). Se trata de pensar las imágenes como una forma de construir identidades y que se contrastan con investigaciones preexistentes en relación con los barrios marginales (Saavedra, 2013, 2015a, 2015b) y de las construcciones identitarias en el campo audiovisual (Arancibia, 2013, 2014, 2015).

Se pretende, finalmente, colaborar con los estudios sobre ciudad, modalidades de representación en el campo audiovisual y las formas en que las memorias se construyen y se entraman en los procesos identitarios locales atendiendo a dos modalidades de construcción diferenciados: el modo ficcional y el modo informativo. De esta manera, se tratará de caracterizar los modos de la confrontación distributiva simbólica sobre los sentidos de la ciudad de Salta apelando al espesor histórico de las representaciones audiovisuales que se construyeron a lo largo de la historia local y perviven en las subjetividades de la región.

\section{Las miradas intersticiales}

La producción de Alejandro Arroz es una de las que ha atravesado y atraviesa diferentes etapas de la historia de la audiovisualidad salteña. Desde los años '80 del siglo pasado -en que participó en las producciones de Miguel Pereira como La deuda interna, La última siembra, entre otras- hasta los cortos documentales que realizó dando cuenta de las formas en que se reprimen las costumbres ancestrales como Hustaj, el rito prohibido pasando por las memorias de los combatientes coyas en la guerra de Malvinas como en Los Vilca Condorí, su producción está atravesada por unos intentos diversos de dar cuenta de los márgenes de una cultura tradicional como la salteña. Las casi cuatro décadas dedicadas a la producción audiovisual están marcadas por la construcción de un repertorio tópico pero a la vez representacional y de formas estratégicas de presentar las imágenes de lo local desde una perspectiva diferenciadas.

En su veta ficcional hay una recurrencia en tomar como base las historias escritas por un narrador y poeta emblemático del Noa como Carlos Hugo Aparicio³. La narrativa de Aparicio tiene como una impronta fuerte el despliegue de estrategias para contar historias que construyen, a la vez, una representación de la heterogeneidad de la región mostrando prácticas, discursos e imágenes que forman parte de los espacios no centrales tanto de las zonas rurales como urbanas. Se trata de una literatura fuertemente impregnada por la crudeza de las prácticas locales de supervivencia y por una referencia permanente al sistema de creencias de la región.

\footnotetext{
${ }^{3}$ Carlos Hugo Aparicio es un escritor nacido en La Quiaca, provincia de Jujuy, pero que se radicó en Salta donde desarrolló toda su labor literaria siendo reconocido y canonizado como uno de los escritores más importantes de la provincia y del país. Entre sus libros más importantes se encuentran los de cuentos que contienen las tres historias que componen el film de Árroz, Trenes del sur una novela de 1988 y poemarios como Pedro Orillas de 1965 o Andamios de 1986. Es miembro de la Academia Argentina de Letras desde 1991. Está considerado como uno de los escritores más destacados del canon literario salteño de la segunda mitad del siglo XX.
} 
Precisamente, el primer largometraje de ficción de Arroz es Luz de invierno, estrenado en el año 2007 y está basado en una serie de cuentos del autor Salto-Jujeño Aparicio. El mismo fue la concreción de un proyecto largamente postergado ${ }^{4}$. Los cuentos que sirvieron de base para el guion del film fueron: 'La búsqueda', 'El último modelo' y 'La pila de ladrillos' que se publicaron en el libro Los bultos de 1974 y que fueron reeditados en Sombras del fondo y otros cuentos de $1982^{5}$.

En la película se narran tres historias sobre personajes que podrían considerarse marginales de la ciudad de Salta. Una de ellas es la de una familia pobre compuesta por el padre dedicado a la albañilería, la madre que se dedicaba a hacer plantines que vendía la hija y dos hijos varones, lustrabotas y changarines. La hija compra una rifa de un auto último modelo y son beneficiados por el sorteo. Debido a las condiciones económicas, la familia no puede costear el combustible necesario para usar el automóvil pero el padre se resiste a venderlo y queda en la puerta de la casa. Con el tiempo, el vehículo se va arruinando y perdiendo partes debido a sucesivos robos. El proceso de deterioro de lo material simboliza el desmoronamiento de la familia y la precarización de las condiciones de vida signada por la pobreza y una sociedad que no logra modificar las condiciones estructurales de la economía.

La otra historia es la de una pareja humilde que consigue una pila de ladrillos para poder construir una galería en su terreno. Cada mañana descubren que los ladrillos van desapareciendo poco a poco, lo que genera una serie de sospechas sobre los vecinos del barrio sobre todo de una mujer anciana. El misterio perdura hasta que descubren que es el mismo protagonista quien a la noche, en medio del sonambulismo, le lleva los ladrillos a una anciana que trata de construir un horno de barro para poder subsistir.

El tercer relato es el de un relojero que prácticamente no tiene trabajo debido al cambio tecnológico que se produjo y que ha hecho desaparecer prácticamente el uso de relojes mecánicos. Como resultado, todas las personas que aparecen en el negocio sólo lo hacen para pedir algún tipo de colaboración. Esta situación es puesta de relieve por la presencia de un mendigo que aparece diariamente y al que el personaje principal de esta historia no puede dejar de darle alguna moneda sin intercambiar más que unas miradas. Un día, el mendigo no aparece lo que genera una desesperación obsesiva del relojero y lo lleva a iniciar una búsqueda incesante. A medida que pasan los días, el relojero desocupado va tomando la fisonomía de su alter ego y deambula por la ciudad mientras asume las mismas conductas que el mendigo para terminar viviendo de la misma manera y en las mismas condiciones. Una historia fantástica que opera con la noción del doble, típica de la literatura de este género.

\footnotetext{
${ }^{4}$ El director salteño había comenzado con la elaboración del proyecto en 1995 y no lo pudo filmar y editar sino hasta el año 2006 (entrevista realizada en enero de 2015). Es importante mencionar que Alejandro Arroz fue uno de los asistentes de dirección del jujeño Miguel Pereira en el film La deuda interna, un ícono del cine de la vuelta a la democracia. Al momento del estreno de este largometraje, el director salteño había producido múltiples documentales premiados en varios festivales del país y del exterior, había filmado para televisión y colaboraba con diversos proyectos de filmación que hacía pie en la región. Asimismo, fue el gestor de la primera 'Semana del Cine Argentino en Salta' en el año 1996, un encuentro que se mantiene con algunos altibajos hasta la actualidad llevando en su haber dieciocho ediciones consecutivas. También fue responsable del área audiovisual de la Secretaría de Cultura de la provincia de Salta. Cfr.: http://pallcafilm.blogspot.com.ar/p/alejandro-arroz.html

${ }^{5}$ Un análisis más detallado de este film se encuentra en la tesis doctoral de Víctor Arancibia (2015) Nación y Puja distributiva. Representaciones sociales, identidades y territorios en la producción audiovisual del Noa 2003-2013 disponible en http://sedici.unlp.edu.ar/handle/10915/46617
} 
Además de Luz de invierno, se aborda otra producción de Alejandro Arroz, una serie ficcional para televisión denominada Historias de las orillas. La misma se encuentra compuesta por ocho historias independientes que se desarrollan en los 'márgenes' urbanos de la ciudad de Salta. Cada de uno de los capítulos de esta serie cuenta distintas historias referidas a la cotidianeidad de los habitantes de barrios ubicados en las periferias de la misma. Dichos relatos también se encuentran basados en la obra literaria de Carlos Hugo Aparicio. De la mencionada serie se seleccionaron para analizar en esta ocasión La pila de ladrillos y Las sobras, siendo éstas historias narradas en claves propias del género del fantástico. La teleserie es una de las producciones consideradas como precursoras en el campo del audiovisual del noroeste argentino en lo que fue el desarrollo de la comunicación audiovisual entre los años 2009 y 2015.

En primer lugar, La pila de ladrillos, que ya se describió con anterioridad, es una narración que constituye una réplica exacta de una de la historia de Luz de invierno. En segundo lugar, Las sobras cuenta la historia de una familia humilde que debe buscar changas ${ }^{6}$ para subsistir debido al hambre que sufren diariamente. Un día al frente de su casa se muda una pareja mayor, considerados de buen pasar económico pero que al parecer han sido desplazados del centro de la ciudad, conservando de alguna manera sus condiciones de vida, pero en otro contexto, en las periferias. A la primera familia le suele llamar la atención la cantidad de sobras que tiran todas las noches los recién llegados, lo que los obsesiona. Debido a la necesidad que sufren y a la situación tan dura de tener a los niños enfermos, al padre se le ocurre hurgar en la basura de los ancianos, lo que permite poner en perspectiva la idea de la dignidad del ser humano cuando surgen las circunstancias más crudas.

La elección de tales producciones tiene que ver con que, en ambos casos, las historias hacen referencia a la vida cotidiana de los habitantes de las periferias de Salta. Las situaciones transcurren en barrios considerados como marginalizados, ubicados 'afuera' del centro principal de la ciudad y dan cuenta de cómo viven, los espacios por los cuales suelen circular, donde se reúnen, hacen compras, de cómo es que se relacionan entre sí y a la vez con las otras capas urbanas que componen la ciudad. Es allí donde desarrollan sus prácticas cotidianas diversas -por ejemplo, las compras realizadas en la verdulería o en el quiosco del barrio por la madre de la familia- las cuales dan cuenta de las múltiples trayectorias, de la convivencia entre 'unos' y 'otros', lo que supone de alguna manera formas de 'trazado' del espacio. Es allí donde se desarrolla y organiza la vida cotidiana, donde se forjan redes de pertenencia, donde se inscriben las prácticas sociales y, por ende, dónde se generan las identidades sociales. Es decir, donde se dan los procesos de reconocimiento -de identificación-, de proximidad y de coexistencia concreta sobre un mismo territorio urbano (Mayol, 1999: 812).

Se puede decir entonces que las producciones de Arroz funcionan como un retrato de las formas de vida en 'las orillas' de la ciudad capital y de los personajes que viven en situación de pobreza no sólo en Salta sino también en el noroeste argentino. Junto a los personajes principales de cada una de las historias, la

\footnotetext{
${ }^{6}$ Se considera como 'changas' a aquellos trabajos poca importancia, realizados de forma circunstancial y pasajera para ganarse la vida de manera transitoria.
} 
cámara se transforma en un modo de registro - casi documental y etnográfico- de varios personajes secundarios, construyendo - de esta manera- una galería de representaciones sobre los habitantes de menores ingresos del noroeste y sobre sus prácticas cotidianas, a la vez que da cuenta del sistema económico imperante desde hace muchos años.

En cuanto a Luz de invierno, cabe mencionar que las condiciones de producción del film están entramadas con el final del gobierno de Juan Carlos Romero quien fue el gobernador que ejecutó las políticas neoliberales en la provincia a lo largo de doce años ininterrumpidos de mandato (entre 1995 y 2007). El 'paisaje urbano’ sufrió dos modificaciones durante esa gobernación que aparecen testimoniadas en el film: el 'maquillaje turístico' del centro comercial de la ciudad con una fuerte reinvención de lo colonial, que aparece sólo aludido en unas pocas imágenes, y la ampliación de las villas y los asentamientos en los alrededores de la ciudad por la pauperización laboral que sufrió la población económicamente activa? .

Hay dos situaciones que se representan en la imagen y en la trama ficcional. Por una parte, las consecuencias de la implementación de estas políticas que se visibilizan y se encarnan en los parroquianos bohemios de un bar que toman vino, los inquilinos de pensiones que viven humildemente con dificultades para pagar la renta, trabajadores ocasionales y changarines que buscan subsistir ante las nuevas condiciones de precariedad laboral, transeúntes varios por las calles de la ciudad, vendedores de tierra para las plantas que circulan ofreciendo su mercancía con megáfonos en carros tirados por caballos que dan cuenta de los modos de la economía informal, jóvenes que se juntan en las esquinas del barrio para charlar y tomar sin que tengan otras obligaciones por la falta de trabajo, gitanos que se dedican a la compra de vehículos, entre muchos otros. Su visionado permite diseñar un mapeo y una clasificación social basada en los modos de construir las representaciones de los trabajadores, de los desocupados y/o sub-ocupados y de sus familias junto con los amigos de cada uno.

Por otra parte, hay una operación de la visibilidad de los contrastes urbanos que se viven entre la Salta del 'primer mundo' pensada para el turismo global, como lo planteaba el gobierno romerista, y la provincia derruida por una economía que renegaba del estado de bienestar y proponía abandonarlo, como figura en los documentos oficiales de la época (Álvarez Leguizamón, 2010: 235). En algunas escenas se produce una convivencia de prácticas y de saberes que vienen de diferentes tiempos de la historia de la ciudad: los carros tirados por caballos junto el auto último modelo; la plaza principal con diseño for export $^{8}$ articulada con las calles de tierra de la villa; entre otros aspectos que dan cuenta de la convivencia en el presente de 'tiempos

\footnotetext{
${ }^{7}$ Sonia Álvarez Leguizamón describe las modificaciones sufridas en la ciudad de Salta a partir de las políticas económicas. La antropóloga salteña sostiene que las modificaciones de la situación 'se produce en un contexto de políticas económicas propias de la gubernamentalidad neoliberal argentina que van de la privatización oligopólica de servicios básicos como el agua, la luz y la energía a la desnacionalización de fuentes básicas de riqueza y recursos energéticos estratégicos, de un mito que dice llevarnos al "primer mundo" a la creciente precarización del trabajo y el aumento de la desigualad y la pobreza' (2010: 245).

${ }^{8}$ Es importante señalar que, en la plaza principal de Salta, la llamada ' 9 de julio', se filmó un comercial para la marca de whisky Chiva's regal y que fue distribuido en todo el mundo. La pieza comunicacional mostraba a una pareja bailando un tango en la plaza salteña y con el fondo de la catedral local. El corto publicitario da cuenta de las formas de articulación entre lo local y lo global. Una copia de este comercial se puede ver en https://www.youtube.com/watch?v=_VLcuqQpZBU
} 
heterogéneos'9. Esta coexistencia de modos de existencia, percepciones, modos de locomoción, saberes, estéticas, entre otros aspectos que se generaron en momentos diferentes y que perviven en el presente, hace que la misma ciudad se viva como heterogénea. La película se plantea como una representación de las formas de vida en sociedades locales que han sido atravesadas por las lógicas globales que modificaron las mentalidades y los haceres cotidianos sin borrar del todo las prácticas y los enseres de épocas anteriores.

Las representaciones audiovisuales, por otro lado, que se registran en cada uno de los capítulos de la teleserie de Arroz se pueden vincular con los imaginarios urbanos, los cuales permiten comprender cómo es que se da el uso de los espacios a partir de la cotidianeidad de los habitantes, lo cual es posible reconocer en ambas producciones. Los imaginarios son considerados no sólo como representaciones de naturaleza mental, sino también como procesos psíquicos perceptivos, motivados por el deseo, que operan como modos de aprender el mundo y que generan visiones y acciones colectivas. En este sentido, se toman como base las representaciones sociales entendidas como mecanismos articuladores entre prácticas y discursos que se construyen en un proceso histórico. Dichas construcciones se materializan en imágenes que se produjeron en circuitos diferenciados como el cine y que posibilitan que su impacto en los modos de percepción y en las capacidades de hacer de los usuarios sea mayor (Cebrelli y Arancibia, 2005, 2013 y 2015).

Es decir, las mencionadas representaciones se "encarnan" o "in-corporan" en diferentes objetos de uso público - como textos, imágenes, arte o arquitectura - de los que se pueden deducir sentimientos como miedo, amor, ira, esperanza, etc., y expresan múltiples fantasías colectivas (Silva, 2006: 83). De ahí que todo objeto urbano no sólo tenga su función de utilidad, sino que pueda recibir una valoración imaginaria que lo dota de otra sustancia representacional.

La ciudad en tal sentido, se considera como un territorio, de carácter no sólo físico, sino también mental (Silva, 2006: 29) y simbólico cuya dinámica se configura por sus habitantes, por las maneras en que 'trazan' o 'marcan' los espacios físicos con su actuar, transitar. En relación a los espacios urbanos se puede problematizar la idea del derecho ciudadano a una vida comunitaria 'digna', que incluya el acceso de consumos colectivos urbanos tales como vivienda, transporte, educación, etc. (Gravano, 2005: 87-88). Pero lo urbano no incluye solamente la ciudad como centro, sino que, como ya se dijo anteriormente, también incorpora lo que se denomina como periferias. Como se puede observar en La pila de ladrillos, el acceso a esos consumos no es distributivamente equitativo. Mientras que por un lado el vecino tiene la posibilidad de acceder a la compra de ese material para ampliar su casa, por otro lado, la vecina y su nieto no tienen ni siquiera para comer. Sus funciones consisten en realizar las gestiones necesarias para resolver los problemas que aquejan al resto de los vecinos, como a sí mismos.

Es así que se debe entender a la ciudad como aquel espacio urbano concebido como el proceso de concentración espacial complejo y sintetizador de distintas esferas de la vida social, económica y cultural.

\footnotetext{
${ }^{9}$ Partha Chatterjee acuña este concepto al momento de pensar las formas de nacionalidad, estado, sociedad y ciudadanía en los tiempos de la postmodernidad y discute la noción de Benedict Anderson de que la modernidad tiene un tiempo homogéneo y vacuo: 'planteo la existencia de un tiempo heterogéneo en la práctica real, incluso, lo afirmo en el caso de las sociedades modernas que viven y habitan en un tiempo heterogéneo, y no en uno homogéneo y vacío. Un tiempo denso y desigual que ha sido llenado de un contenido' (2008: 25).
} 
Implica lo estructural, en el sentido del valor de uso de la ciudad misma y de la dinámica social; como realidad cultural en vinculación a la construcción de producciones de sentido compartidas; y como producción material e instrumento del proceso de dominio socio-político (Gravano, 2005: 87-88).

Cada una de las producciones audiovisuales acá analizadas dan cuenta de una de las formas de la construcción de representaciones sociales de los grupos involucrados (en este caso en particular de los sectores marginalizados de la sociedad salteña), de los espacios que habitan y de los que transitan, los modos de circulación y sus formas de habitar los espacios, las prácticas cotidianas de supervivencia entre otros aspectos. En este sentido, se transforman en un documento de las formas en que se retratan determinados sectores de la sociedad tratando de construir un símil de la mirada del margen en el campo de la imagen televisiva y cinematográfica.

\section{Mapeando la ciudad, movilidades múltiples entre capas urbanas}

Cabe recordar que Salta es una provincia situada al noroeste del país, compuesta por 1.215.207 habitantes en una superficie de $155.488 \mathrm{~km}^{2}$. El municipio capital tiene una población de 535.303 habitantes, siendo considerada la ciudad más poblada de la provincia. Su área metropolitana, denominada Gran Salta, se compone por once municipios, según los datos obtenidos de acuerdo con el Censo realizado en el año 2010. El centro de la misma suele ser objeto de los discursos del turismo actual, los cuales retoman las representaciones forjadas a principios del siglo XX acerca de lo colonial y las objetivan en sitios y lugares específicos que refuerzan el imaginario salteño y sus valores (Álvarez Leguizamón, 2010: 52).

En tal sentido, las representaciones que más circulan sobre Salta son aquellas que la caracterizan a partir de sus rasgos tradicionalistas y conservadores, por el arraigamiento a costumbres que se remontan a la época colonial y por una adscripción religiosa fuerte, elementos que conforman su identidad (sobre todo en la cristalización ${ }^{10}$ que se realiza desde las propias estructuras hegemónicas de la sociedad salteña). Esto se puede ver en una política sostenida en el último cuarto de siglo que la plantea como sede de importantes referencias patrimoniales plasmadas en la arquitectura, los monumentos, los museos y las distintas manifestaciones artísticas y folklóricas que históricamente fueron atractivas para el turismo (Troncoso, 2013: 2) y que fueron construyendo una representación que apunta a valores tradicionales vinculados a la cultura local.

La ciudad, como ya se sostuvo, es pensada como próspera y turística por la utilización de los valores de conservación como bien de consumo, lo que se visualiza es lo culto -en sentido tradicional- lo que se puede observar en los teatros, en los edificios de estilo colonial, la catedral, la plaza principal, una música particular y una galería de escritores reconocidos y que alimentan el slogan de 'tierra de poetas y de cantores. De

\footnotetext{
${ }^{10}$ Definimos a las representaciones sociales como un 'como un mecanismo traductor entre las prácticas y los discursos en tanto posee una facilidad notable para archivar y hacer circular con fluidez conceptos complejos cuya acentuación remite a sistemas de valores y a modelos de mundo de naturaleza ideológica. Gran parte de la capacidad de síntesis se debe a su naturaleza parcialmente icónica, fruto de que -en algún momento de su circulación- se ha materializado por medio de este tipo de signos y, por lo tanto, su percepción, su reconocimiento y su significación son deudores de algún tipo de imagen que la refiere y con la cual se identifica' (Cebrelli y Arancibia, 2005, 2014). Esto hace que se produzca un efecto de monosemia que oculta la complejidad de la misma y que esa cristalización genere la sensación de estatismo y poco cambio con que muchas veces se presenta.
} 
esta manera se construye la imagen de una ciudad y una provincia que es linda, amena y 'visitable', 'tan linda que enamora' como dice el último slogan del Ministerio de Turismo y Educación de la Provincia. Estos elementos configuran el centro principal de la ciudad. Este no es lo que habitualmente aparece en la construcción representacional de las producciones aquí abordadas.

Pero, la ciudad no sólo es aquel centro, pues en la misma, un poco más alejadas de ese núcleo turístico, existen periferias distintas. Es allí donde muchos ciudadanos habitan, donde transcurren sus vidas, donde se desarrolla su cotidianeidad y por lo tanto donde se hacen visibles las desigualdades sociales. Se puede decir entonces que el territorio actual de la ciudad se constituye como un espacio social heterogéneo, consecuencia de una estructura social segmentada y atravesada por configuraciones sociales diversas. La zona sudeste de la ciudad de Salta es nominada como una periferia, integrada por el barrio Gauchito Gil, a la que suman los barrios de Solidaridad, Sanidad, Primera Junta, La Paz, Libertad, entre otros. Se encuentra caracterizada por una serie de problemáticas tales como contaminación, delincuencia, pobreza, entre otros, que inciden en cómo se va configurando la cotidianeidad de sus vecinos y por ende sus identidades.

Desde los mismos títulos como Historias de las orillas o Luz de invierno apuntan a la construcción de una imagen no habitual, una imagen que quiebra y confronta con las sucesivas cristalizaciones mencionadas. La opción por las periferias apunta a esos otros espacios existentes en la ciudad. Esas periferias, consideradas como un punto de estigmatizaciones constantes, no sólo por el resto de la población, sino también por los medios, los cuales conforman a estos grupos como una otredad que se debe excluir (Reguillo, 2008: 5) van conformando una galería de representaciones de las formas de exclusión circulantes en esta cultura.

Cada una de las historias audiovisuales acá analizadas da cuenta de una ciudad como un espacio de interacciones, pero a la vez de conflictos, de desigualdades, donde se da una división tanto simbólica como material entre centro/s y periferias (Silva, 2006: 27), partes que se encuentran en tensión constante (Ortíz, 1998). Basta pensar en los modos en que la ciudad aparece representada en cada escena del film o de la teleserie: espacios de pertenencia como el barrio marginal donde los servicios son escasos y donde recalan los excluidos por la falta de trabajo como en el caso de 'Las sobras' o las formas de las viviendas en Luz de invierno. El 'centro' material y simbólico de la ciudad sólo aparece como un espectro que se sabe que está pero que no forma parte de la habitualidad de los tránsitos. Sólo en la escena final del film se lo puede ver de lejos, una toma que se realizó desde un barrio llamado 'Floresta' y que es la contracara de la vista del 'Cerro San Bernardo', mirador turístico por excelencia de la ciudad de Salta.

El territorio actual de la ciudad de Salta se constituye como un espacio social en el cual se dan situaciones de desigualdad y pobreza de larga data, resultado de una estructura social segmentada y atravesada por configuraciones sociales diversas. Las imágenes seleccionadas y las piezas audiovisuales son un testimonio de este modo en que se construye una ciudad cuyos índices de desigualdad son importantes. En tal sentido, se considera a la ciudad como una producción material/simbólica, inserta en un proceso de transformación y socialización permanente, que no se reduce al mero espacio físico de aglomeración, sino que adquiere valores, identidades e imaginarios construidos históricamente. Esto aparece representado en las superficies 
audiovisuales plasmado en las formas en que los habitantes de la ciudad viven y subsisten, las formas de las economías informales y las confrontaciones entre los sectores de la sociedad que se encuentran en conflicto constante por los medios necesarios para sobrevivir.

No sólo se vive en la ciudad sino que se vive la ciudad (Gravano, 2010: 1) y esto es lo que las producciones audiovisuales mencionadas escenifican. En este sentido, son las prácticas y las acciones, las que le dan sentido a las situaciones vividas en la ciudad. Es decir, son relaciones significativas, respecto de un espacio social que se presenta como complejo, heterogéneo y a veces discontinuo (Gravano, 2005: 35). Es que la ciudad no se reduce a sus características materiales, ya sea edificaciones, plazas y parques, calles, avenidas y autopistas, etc., sino que involucra una multiplicidad de discursos, imágenes, representaciones y relatos que son elaborados por quienes viven en ella y que les posibilitan establecer vínculos con el espacio urbano (Segura, 2015: 35). Es decir que todo ciudadano tiene vínculos diferentes con una u otra parte de su ciudad, y su imagen esta embebida de recuerdos y significados (Lynch, 1959).

Salta, en las últimas décadas, ha sufrido transformaciones urbanas importantes lo que llevó a que muchos ciudadanos se hayan visto obligados a dejar los centros y a ser desplazados a las periferias. La consecuencia directa es un sector de la sociedad salteña que se habita el margen ${ }^{11}$, que se le niega una concreta existencia, ya que no se le reconocen sus derechos básicos como ciudadanos, a cubrir sus necesidades primordiales, como lo es la vivienda digna. 'Vivir al margen' se contrapone a 'vivir en el centro', es decir un centro de la ciudad de Salta que se muestra como algo luminoso, mientras que las periferias como algo oscuro. Quienes viven al margen son naturalmente condenados a la indiferencia, al olvido.

Uno de los rasgos distintivos se lo puede rastrear al interior de la ciudad donde se pueden identificar distintas periferias, es allí, en cada barrio, donde los vecinos edifican sus casas, organizan la vida cotidiana, forjan redes de pertenencia, donde se inscriben las prácticas sociales y por ende dónde se generan las identidades sociales. Es así que la realidad del centro de la ciudad dista de la realidad que se presenta en las periferias. Dos realidades que parecen muy lejanas, pero que conviven en una misma ciudad, que en múltiples ocasiones parecen ser muchas y que las separan fronteras internas que se encuentran en contacto.

Para poder analizar cómo es que se referencian las zonas periféricas de la ciudad de Salta, en contraposición a las imágenes de la ciudad como turística y tradicional, es necesario hacer un mapeo de cómo se encuentra diseñada la ciudad. Se podría decir que el núcleo de la ciudad se encuentra en el micro centro o centro principal donde se ubica el casco histórico destinado a la administración pública, a la industria hotelera, al comercio, como lugar de ocio, de compras, de bares nocturnos, restaurantes, peñas folclóricas, galerías de arte, siendo así lugar turístico privilegiado dentro de la ciudad, atrayendo no sólo a turistas, sino también a la misma población. En las producciones de Alejandro Arroz, la referencia a este centro es escasa, sólo se la muestra para identificar la Relojería en Luz de invierno y como aquel lugar en el cual los jóvenes de la fami-

\footnotetext{
11 Siguiendo a Fassin, existen diversas formas de representar espacialmente a la sociedad: adentro/afuera, arriba/abajo, centro/periferia. Lo que tienen en común, es un mundo compartido entre dos categorías de individuos, una que se corresponde con la norma social dominante y la otra que se ve expulsada hacia una frontera. Es decir, ubicados ficcionalmente en los márgenes del seno de la sociedad, o sea del 'lugar' en el que se toman las decisiones (Vasilachis de Gialdino, 2013: 132).
} 
lia de La pila de ladrillos, trabajan como lustrabotas o bien vendiendo las plantas. Pero no describe o exhibe sus monumentos, sus plazas, sus museos, es decir que no alude a aquellas características significativas ligadas a la construcción del centro destinada al turismo. La opción estética es por posicionar las cámaras y construir una mirada que intenta reconstruir el modo de mirar de los grupos que habitan 'las orillas'. Es una elección que se está transformando en recurrente en las producciones del NOA de las últimas décadas basta pensar en las producciones Lucrecia Martel, Bárbara Sarasola Day, Exequiel Radrusky, entre otros.

Luego es posible identificar otra capa urbana que se encuentra construida por aquel espacio intermedio, es decir esos barrios que se encuentran un poco más allá de los límites de ese micro centro, pero que no llegan a estar ubicados geográficamente en las periferias, un espacio intermedio de negociación entre sectores concomitantes. Un ejemplo de ello es el barrio Villa Las Rosas, lugar cercano a la cárcel y al cementerio junto con el hospital neuropsiquiátrico, en el cual los jóvenes en Luz de invierno hacen el intento de robar nafta para colocarle luego al auto que ganaron en la lotería. Este espacio limita con una de las zonas de ingreso a la ciudad ya cerca del mencionado barrio se encuentra ubicada la terminal de ómnibus que llegan tanto de los departamentos de la provincia como de fuera de ella.

La última capa es aquella integrada por grupos sociales que viven a una distancia considerablemente lejana del centro principal. Barrios, asentamientos, villas que por lo general carecen de las condiciones mínimas para su vida en condiciones dignas, como ser servicios esenciales tales como luz, gas, agua, cloacas, etc. Esto implica considerar el espacio donde habitan las familias protagonistas de las historias de Arroz y que de alguna manera el cineasta representa como 'afuera de la ciudad'. Esto es posible observarlo cuando al final de Luz de invierno, se observa la ciudad desde lo alto de un cerro, estableciendo un claro contraste entre una ciudad vista a la distancia iluminada y un barrio completamente a oscuras.

Ahora, es necesario pensar en que tales capas que estructuran el espacio urbano de la ciudad no se mantienen cerradas, clausuradas, sino que en realidad los habitantes penetran constantemente entre las mismas. Estas formas de interpenetración en los círculos que componen la ciudad aparecen en las producciones de Arroz, cuando los jóvenes se trasladan desde un barrio ubicado en la periferia, hacia el centro principal para trabajar. Otro ejemplo que se puede mencionar es cuando la familia de Luz de invierno debe dirigirse a recibir el auto, premio ganado en la lotería. Otro caso es el del intento de robo, donde los jóvenes penetran una capa intermedia de la ciudad para llevar a cabo su hecho delictivo.

A pesar de las distancias -físicas y simbólicas- que separan las diferentes capas urbanas, las mismas forman parte de una misma ciudad y contribuyen a la elaboración de un mismo relato identitario salteño. Sólo así es que se puede dar cuenta de cómo es que se va construyendo esta identidad, en relación a las diversas maneras de vivir en la ciudad en la misma, es decir planteándola como un tejido socio-políticoespacial urbano fragmentado (León, Meave y Ramos, 2009: 2). Es así que existen diversas realidades que conviven en un mismo espacio urbano, realidades que constantemente cambian, que no son siempre las mismas, pues las fuerzas sociales se mueven, lo que posibilita poner en cuestión las desigualdades, asimetrías sociales, culturales, económicas, estructurales que se viven al interior de Salta. 


\section{Discurso informativo y formas de construir identidades}

En la elaboración de identidad(es), los medios de comunicación tienen un papel central, pues construyen ideas de mundos posibles, a través de las agendas que establecen y que siempre son impuestas por sectores determinados como hegemónicos. En ese sentido se parte de anticipar que las representaciones permiten construir un sentido y por ende la mirada (Rodríguez, 2011). Por lo tanto, los medios de comunicación, otorgan valores y visibilidades fomentando ideologías e influyendo en la opinión pública. Ésta es entendida como un proyecto político dinámico, que designa una masa segmentada de opiniones particulares en las que se expresan intereses divididos y hasta conflictivos. Los medios de comunicación se pueden considerar entonces como escenarios de debates públicos, lo que posibilita reflexionar sobre la importancia que los medios masivos de comunicación tienen como actores sociales, en cuanto a la construcción de la opinión pública en una sociedad compleja, como la salteña.

A la vez, las representaciones mediáticas son formas de construcción que tienen una capacidad de amplificación que no tienen otras representaciones y funcionan como operadores identitarios en tanto permiten identificaciones posibles (Cebrelli y Rodríguez, 2013). En el discurso de la información que se pueden observar en los telediarios locales se pueden ver la pervivencia de ciertas representaciones cristalizadas de las representaciones de los grupos que habitan los márgenes. Hay un estatismo de la representación que es concomitante con las imágenes televisivas. Esto confronta con los discursos publicitarios sobre la ciudad de Sata que históricamente se han destinado principalmente al turista intentando construir representaciones sobre los lugares que ya se han mencionado anteriormente y que traten de influir en las percepciones de quienes no conocen el espacio concreto de la ciudad. Tales lugares se pueden considerar como 'marcas', donde lo que se encuentra en juego es el poder del capital simbólico colectivo. Las marcas-ciudad se relacionan con una valorización subjetiva del espacio, como producción de significados para la ciudad, es decir que son una especie de "marca de distinción" para el lugar y por ende para sus habitantes. Se trata de una estrategia que consiste en una inversión simbólica que es planificada y desarrollada por ejemplo en Salta desde la publicidad (Harvey, 2007: 428). Es así que el gobierno provincial ha empleado una serie de herramientas discursivas -respondiendo a los intereses de los sectores dominantes de la sociedad-que juegan un papel central, porque apelan a relatos históricos, interpretaciones, significados de recuerdos colectivos, significaciones de prácticas culturales que contribuyen a la construcción de reivindicaciones que se sustentan en la singularidad, autenticidad, particularidad y especialidad de la ciudad (Harvey, 2007: 428).

Las piezas informacionales relevadas en los telediarios locales generalmente reproducen ciertas representaciones circulantes. Las tres noticias recabadas durante las emisiones del año 2016, a modo de muestreo, del corpus seleccionado hacen referencia al barrio Gauchito Gil, ubicado en la zona sudeste de la ciudad de Salta (considerada como una periferia marginalizada), el cual se fundó como asentamiento en el año 2009.

La primera noticia de Canal 4 de Salta se titula: "Calles intransitables en barrio Gauchito Gil” y en la misma se da cuenta de un problema ocasionado por las lluvias, lo que volvió al lugar -según la visión del 
medio- como 'intransitable'. El periodista a cargo del móvil le hace una entrevista a una vecina del barrio Gauchito Gil, Luciana Yapura, quien se encuentra con su hijito pequeño. De fondo, se muestra una calle por la que circulan vehículos y en la que se ven algunas casas del barrio. La conversación comienza con Luciana sosteniendo que 'no hay solución de nada', a lo que el periodista le dice que para 'salir de su casa' tuvo que hacerlo por un 'camino de piedras', la vecina le contesta que 'todos los días es así'. Inmediatamente a esto, la cámara enfoca las calles estrechas, llenas de agua, barro, y de yuyos altos a los lados. Se focaliza en la 'desesperación de los vecinos por no poder salir', en la tardanza y falta de presencia estatal, ya sea de Defensa Civil que 'llega tarde' o a la no respuesta de la Municipalidad. Debido a ello, se menciona una práctica de autogestión comunitaria, que tiene que ver con la contratación de camionadas de tierra por $\$ 50$ pesos para rellenar los pozos donde se junta agua contaminada, es decir aquella capacidad para actuar y resolver sus propias necesidades de manera solidaria entre vecinos. Se solicita la apertura de calles, el nivelado de los terrenos. El periodista guía la conversación nuevamente a que cuando llueve 'los vecinos quedan atrapados y no pueden salir hasta que baje el agua', a lo que Luciana responde que cuando eso sucede 'no puede salir a comprar ni nada', o sea que este hecho que se denuncia imposibilita la normal circulación y realización de sus prácticas cotidianas. Luego la cámara vuelve a enfocar la calle, donde se encuentra caminando a la distancia una mujer con una bolsa de compras en la mano, a su lado se ubica una niña pequeña y un perro. La charla luego se enfoca en la pregunta del periodista por la humedad y los insectos que deben aguantar luego de que baja el agua, a lo que la vecina contesta que sí aparecen bichos. Posteriormente, se le consulta acerca de si es que ha habido promesas de obra más allá de que es un 'asentamiento, que no tiene factibilidad, o forma de solución. La vecina sostiene que hay compromisos de funcionarios que han hablado con sus delegados, pero que 'no vienen'. Además se le pregunta acerca de las posibilidades de reubicación y finalmente el periodista le consulta acerca de aquella sensación que le genera la situación, a lo que Luciana responde que tiene pena, que las promesas no se cumplen y que es necesario que 'les den una mano' 'porque los chicos se enferman'. El sonido que predomina es el ambiente del barrio que dificulta la comprensión de las palabras y no se puede percibir la intención de poder limpiar los sonidos para una mejor audibilidad.

En la segunda noticia también de canal 4 de Salta, el zócalo cita: 'RECLAMOS POR OBRAS Y SERVICIOS. Vecinos de Gauchito Gil cortaron ruta 26'. Se le da la palabra a una vecina del barrio, quien sostiene que 'perdió todas sus cosas' que no la ayudan de la Municipalidad ni de la Cooperadora, que ella vive con su hija. De fondo se muestra su casa, luego a la par de la imagen de la vecina se divide la pantalla y se colocan imágenes de lo que está sucediendo respecto del corte de la ruta 26 , donde se encuentran los vecinos de espaldas y algunos policías observándolos. La vecina invita a los medios a entrar a su casa para que vean en las condiciones en la que están viviendo. A continuación, se le da la palabra a quien parece ser una funcionaria o bien a alguien de algún organismo público. La misma plantea que se habló con los delegados de 'este barrio que es un asentamiento', lo que pone en evidencia que el barrio como en la noticia anterior se nomina como 'asentamiento', a pesar de que sus vecinos lo hagan como 'barrio' marcando y reacentuando el sema de la carencia que este concepto tiene. Intenta aclarar que 'si bien la zona no es urbanizable al día de 
hoy, hay un montón de asentamientos que se han transformado en urbanizaciones con un gran trabajo de ingeniería'. Pero resalta que este caso particular implica mayor esfuerzo debido a que fue zona de cortada de ladrillos por lo tanto quedaron muchos zanjones. Sostiene que el compromiso con la Secretaría de Tierra y Hábitat consistía en 'darle forma a este barrio y abrir la calles, previo tapado de zanjones o lagunas, mediante el desagüe de las mismas'.

En la tercera noticia de La Gaceta de Salta en la que se hace mención a las dificultades que sufren los vecinos debido a las lluvias. La misma se inicia con una presentación del medio de comunicación, lo que da la pauta de que se trata de un informe editado para ser presentado en el noticiero. Las imágenes muestran el perfil de una casa del barrio, con el patio lleno de barro y las gotas de lluvia cayendo desde el techo. Seguido por las calles llenas de barro, piedras y agua que circula como pequeños ríos, de fondo se escucha música de foso, cuya melodía alude al sentimiento de tristeza, melancolía. En el campo de la imagen se puede observar a un anciano circulando con un paraguas e inmediatamente se exhiben imágenes del interior de una vivienda, los secadores del piso se encuentran ubicados al lado de la puerta del patio, el techo de chapas gotea. Un plano detalle de los pies de dos personas, una de ellas de un niño, luego se hace un paneo general de la familia en la vivienda. Seguidamente se le da la palabra a una integrante de tal casa quien sostiene que 'siempre que llueve, se inunda todo, entra por todos lados el agua' muestra su patio, la ropa colgada en sogas. El zócalo cita: 'TESTIMONIOS. Vecinos cuentan cómo sufren con cada lluvia'. La vecina cuenta que su casa es un río y que el tránsito de vehículos empeora la situación. Se vuelve a colocar la misma música de foso. Luego se le da la palabra a otra vecina anciana, quien también refuerza la idea del ingreso de agua a su casa y agrega que su pozo ciego se rebalsa y el agua servida sale a la superficie, por lo que deben limpiar y tirar fenelina. La periodista entra a la casa de la señora y graba imágenes del patio y de las entradas de agua. Por último, se muestras imágenes de muchas prendas de ropa apilada, doblada, además de zapatillas, en su mayoría de niños, en un lugar que parece ser un Centro Integrador Comunitario (CIC), pues una señora sostiene que los niños no tenían zapatillas secas y ahora tienen, que se les da desayuno, almuerzo y que reciben ayuda de la Cooperadora y de la comunidad. El informe se cierra con la misma música y se detallan los encargados de imágenes, cámara, edición y el periodista.

Se puede decir que en las tres noticias se hace hincapié en las carencias de los habitantes de esta zona periférica, en la ausencia de autoridades de gobierno. Las estrategias de construcción de tales piezas informativas tienen que ver con la nominación del barrio como asentamiento no urbanizable, haciendo referencia a la pobreza, a las consecuencias negativas de asentarse en terrenos no aptos para la vida. Estos medios eligen en tales casos mostrar a los vecinos del barrio como pertenecientes a un sector de la sociedad que se considera como "precario", "pobre”, "inundable”, "intransitable”, es decir que se lo califica construyendo un campo semántico donde predominan los semas negativos; ubicándolo y reconociendo una situación de extrema pobreza. Es así que se pone en circulación en el imaginario, representaciones que se actualizan constantemente, reproduciendo los discursos de la hegemonía, imponiéndolos a la población y dejando, como consecuencia, a muchos grupos sociales en una situación de inferioridad, de asimetría y hasta de subalternidad. 


\section{Entre convergencias y divergencias}

Las imágenes informativas y ficcionales dan cuenta de un sistema representacional que es propio de la cultura local, de un sector de dicho sistema que habitualmente es invisibilizado por la importancia de las representaciones dominantes. En ambos casos, se pueden rastrear procesos que son concomitantes en tanto, como lo sostiene Gustavo Aprea (2012), la ficción es una forma de documentar la realidad y las informaciones y los documentales utilizan formas de ficcionalizar la realidad. Se trata de procesos de construir las representaciones sociales que funcionan como mecanismos traductores y que impactan de manera diferenciada en los modos de percibir la realidad (Cebrelli y Arancibia, 2005, 2016). Son estrategias concomitantes que operan de manera transversal en los discursos ficcionales y en los informativos, tanto en medios televisivos, como cinematográficos. A la vez, un relevamiento de las formas de construir representaciones audiovisuales de grupos subalternizados permite ver las diferencias internas en el sistema representacional.

Por una parte, se pueden rastrear estrategias que no hacen más que consolidar las representaciones más cristalizadas sobre los sectores subalternos que apuntan a la inmovilidad de los mismos apelando a estrategias visuales como la entrevista a cámara fija con un movimiento de zoom como sólo recurso para aproximar la imagen de la persona que está exponiendo la problemática. Los inserts de las noticias tienen una función descriptiva y en la que se pone en el centro de la imagen sólo los elementos que dan cuenta de la precariedad de las formas de vida de estos grupos. El estancamiento visual y la opción por el enfoque de objetos producen y reproducen la situación de aislamiento de cada una de las personas que aparece en la imagen. Se trata de una estrategia habitual de los telediarios locales que se ponen en funcionamiento cada vez que se entrevista a sectores considerados marginales de la ciudad (Cebrelli y Arancibia, 2017).

A nivel de la construcción del discurso verbal, los zócalos como se señala en el parágrafo anterior no hacen más que reforzar la imagen de 'sufrimiento' por parte de los pobladores de estas zonas marginales de la ciudad. El sema de 'quietud' vinculado con el 'padecimiento' y cierto grado de resignación' son los elementos centrales con que se construye con esta idea; es una representación de que son receptores pasivos de las acciones de los gobiernos, de las inclemencias climáticas o de la falta de atención, refuerzan la idea de 'quietud' que se ha planteado en la imagen influyendo en los modos de percepción de las audiencias.

El sonido empastado y técnicamente poco claro por las inclemencias climáticas pero a la vez por la falta de trabajo sobre el mismo hace que se refuercen las ideas de zona límite de la ciudad donde todo se va derruyendo. Se trata de un sonido en el que, en el plano del registro verbal, el entrevistador también guía el razonamiento y las palabras de las personas que entrevista gestando un campo de interlocución en el que las voces autorizadas siguen estando en mano de los medios de comunicación. De alguna manera, el entrevistador es quien mediante un mecanismo de ventrilocuismo va incidiendo sobre las palabras del entrevistado.

Por su parte, en las estrategias ficcionales se busca contar la cotidianeidad de las prácticas. Es elección por la reconstrucción de las prácticas habituales transforma a los sujetos en actores sociales que están permanente en movimiento y en tránsito en busca de la supervivencia y de la búsqueda soluciones a los pro- 
blemas diversos con los que se enfrentan. El sema constitutivo de este tipo de estrategia es el del movimiento.

Se trata de una apuesta a la circulación como modo de representación de los sectores sociales. Los jóvenes van en busca de dinero, de las maneras múltiples y posibles que les brindan prácticas legales y de algunas que eufemísticamente se pueden denominar como 'alternativas'; las formas de consumo que obligan a moverse del lugar del barrio para conseguir lo que necesitan para ello; asistir a las instituciones educativas que se encuentran fuera de la zona que habitan, entre otras prácticas que se textualizan.

Los diálogos también narran los recorridos por los diferentes lugares de la ciudad que, si bien no son vivenciados como propios, tampoco les son ajenos por cuanto constituyen el paisaje de sus recorridos habituales aunque sea de manera hostil. Se trata de un mapeo construido a partir de los cuerpos en tránsito y de la mirada que registra los lugares para poder trazar alternativas de tránsito. Cada uno de estos recursos va acompañado de un movimiento también constante de las cámaras que acompañan los recorridos y varían las estrategias de focalización y las técnicas con que se representa el movimiento.

El préstamo de estrategias visuales entre un formato y otro hace que se pongan en funcionamiento los emparentamientos que acercan una producción con otra. En ambos casos, hay un centro en el sistema referencial de las representaciones aparece como ausente, meramente referido por medio de frase o de imágenes sugeridas. Al modo de la imagen final de Luz de invierno donde en el fondo de la imagen se vislumbra lo que sería el centro salteño, en las referencias de los telediarios el centro funciona como lugar de referencia pero que espacial y simbólicamente no permite ningún acercamiento posible. Hay una desaparición de las referencias del centro de la ciudad, salvo como espectral o en ocasiones muy especiales. Se trata de una presencia fantasmática que sólo se pone en pantalla para reivindicar su fuerte localización y su rol de generador de regularidades.

En ambos casos, las estrategias visuales vinculadas a los lugares en los que habitan los personajes o las personas tienen una función descriptiva de los hábitats. Se muestran las paredes, las puertas, las ventanas y los pisos en primera instancia y en el paneo se ven las condiciones de vida. A la vez, se trata de describir visualmente cada uno de los contextos en los que se encuentran las viviendas para que los destinatarios puedan contrastar con las memorias perceptuales de los lugares con mejores condiciones de servicios y se pueda establecer la distancia entre las propias condiciones de vida y la de 'los otros'.

En ambos casos, se produce -como se dijo anteriormente- en el nivel de la recepción la contrastación entre las imágenes de la representación destinada a la captación de recursos mediante el turismo y las condiciones de vida de una Salta que queda excluida de la 'marca ciudad'. Se trata de dos identidades en puja pero que se encuentran en puntos de circulación diferenciada. La imagen de la ciudad, como limpia, amena y visitable, abierta al turismo no puede ser única y homogénea, sino que más bien dentro de la misma se producen muchas otras identidades que se cruzan, se cortan, se atraviesan entre sí; generando imágenes 'otras' que se contraponen a la primera. 
Ambas construcciones apelan a memorias diferentes y a temporalidades múltiples que fueron aportando significaciones especificas en el desarrollo temporal de cada una de las representaciones en conflicto. Se trata de una puja representacional que tienen formas diferentes de aportar a la construcción de la iconografía de la ciudad que se testimonia en diferentes soportes visuales. Se puede percibir un espesor temporal, entendido como la persistencia de ciertas imágenes y representaciones a lo largo del tiempo y que se mantienen a veces en estado de latencia y otras pasan al centro de la visibilidad pero que van dando cuenta de la densidad semántica de una representación (Cebrelli y Arancibia, 2005), que va complementando una representación de Salta compleja y que responde a cadenas equivalenciales diversas. Se trata de representaciones que responden a órdenes diferentes de la cultura y que permiten explicar el mundo a la vez que brindan sistemas para las autoadscripciones identitarias de actores diversos de la sociedad.

Las representaciones textualizadas en los audiovisuales analizados organizan el orden simbólico de una sociedad (Cebrelli y Arancibia, 2008; Rodríguez, 2008) siendo reconocidas como mecanismos traductores que tienen la capacidad y facilidad para archivar y hacer circular con fluidez conceptos que remiten a sistemas de valores y a ciertos modelos de mundo de naturaleza ideológica (Cebrelli y Arancibia, 2005). De este modo las representaciones sociales establecen una relación particular con las memorias de los diferentes actores y grupos (Cebrelli y Arancibia, 2011), es decir que se considera a la representación social como una articulación que posibilita pensar la relación del sujeto, las adscripciones identitarias y las formaciones discursivas como correspondencias no necesarias, como contingencias que reactivan los procesos históricos y que se entraman y se leen en los intercambios comunicativos que dan cuenta de las complejas trayectorias que construyen las identidades (Cebrelli y Arancibia, 2012).

\section{Entre plasticidades y rupturas}

Este trabajo es un intento de encontrar variables que permitan construir una mirada que atraviese formatos audiovisuales diversos y que funcionen como estrategias metodológicas para abordar la topicalización de las ciudades en las producciones audiovisuales en sus diferentes formatos y un relevamiento de las estrategias visuales con sus posibles incidencias en el sistema perceptual tanto en la región como fuera de ella. A la vez, se trata de dar cuenta de las interacciones entre los géneros y los formatos audiovisuales en las formas en que construyen sus verosímiles y sus sistemas de referencias representacionales.

En cuanto a lo analizado, tanto en los telediarios respecto del caso testigo del barrio Gauchito Gil, como en las narrativas cinematográficas y en las series ficcionales, las variables que se consideraron fueron la construcción de las representaciones que se realizan en función de las estrategias tanto en el plano del discurso verbal como en el visual y sonoro. En cada uno de los casos se trató de ver las interacciones entre lo informativo y lo ficcional partiendo de la base que hay ficcionalización del discurso informativo y documentación en el registro ficcional.

Tal como lo plantea Didi-Huberman, las plasticidades tienen que ver con el juego de préstamos, resignificaciones y apropiaciones pero, a la vez, por las formas en que los discursos se entraman en las actuales 
condiciones de producción. Al mismo tiempo, se ha trabajado sobre las formas en que las dimensiones temporales de cada una de las representaciones textualizadas en el espacio audiovisual dan cuenta de espesores temporales diversos que condicionan muchas veces no sólo las formas de producción sino también las formas de recepción de los discursos informativos y ficcionales.

Estas interacciones van construyendo, de manera solidaria y concomitante, las imágenes de una ciudad que define su identidad por el dato concreto de la información, pero a la vez por la construcción simbólica que realizan cada una de las puestas en imagen. Estas modalidades de representación presentes en tales tipos de producciones, no sólo impactan en un nivel macro de la ciudad, sino también en el proceso de construcción identitario de las periferias -como ser la zona sudeste y en particular el barrio Gauchito Gil-que suelen ser visibilizadas de manera negativa. Se trata de procedimientos que van de la obnubilación a la ceguera que encandilan y sugieren, que permiten vislumbrar ciertos espectros de ciudades de larga data que se actualizan en cada puesta en pantalla, en cada emisión, en cada nuevo visionado. Golpes de tiempo, golpes de mirada, golpes de sentido que abren nuevas puertas y nuevos tiempos por recorrer. 


\section{Referencias bibliográficas}

Álvarez Leguizamón, S. (2010). Poder y Salteñidad. Saberes, políticas y representaciones sociales. Salta: Centro Promocional de Investigaciones en Historia y Antropología (CEPIHA).

Aprea, G. (2012). Filmar la memoria. Los documentales audiovisuales y la reconstrucción del pasado. Buenos Aires: UNGS.

Arancibia, V. (2013). “Confrontaciones distributivas en el campo audiovisual. Hacia la construcción de visibilidad(es) de la diversidad". En prensa.

Arancibia, V. (2014). “Confrontaciones distributivas en el campo audiovisual. Hacia la construcción de visibilidad(es) de la diversidad”. En: Nicolossi, A. (coord.) La televisión en la década Kirchnerista. Democracia audiovisual y batalla cultural. Buenos Aires: UNQui.

Arancibia, V. (2015). Nación y puja distributiva en el campo audiovisual. Identidades, memorias y representaciones sociales en la producción cinematográfica y televisa del NOA (2003-2013). UNLP: Sedici http://sedici.unlp.edu.ar/handle/10915/46617

Cebrelli, A. y Arancibia, V. (2005). Representaciones sociales. Modos de mirar y hacer. Salta: CEPHIACIUNSA.

Cebrelli, A. y Arancibia, V. (2008). "Trampas de las representaciones. Apuntes para el análisis de las coberturas mediáticas de problemáticas referidas a pueblos originarios”. En: Actas de las XII Jornadas Nacionales de Investigadores en Comunicación Rosario. Santa Fe- Rosario: UNR.

Cebrelli, A. y Arancibia, V. (2011). "Prólogo Las representaciones y sus márgenes. Identidades y territorios en situación de frontera". En: Revista Reflexiones Marginales. Disponible en http://v2.reflexionesmarginales.com/index.php/numero-anterior/10-septiembre-2011/dossier.

Cebrelli, A. y Arancibia, V. (2012). "Representaciones Sociales y Fronteras. Las prácticas comunicacionales en enclaves multiculturales". En: Actas XI Congreso de Asociación Latinoamericana de Investigadores en Comunicación (ALAIC).

Cebrelli, A. y Arancibia, V. (2012). "Representaciones sociales. Abordajes teóricos y metodológicos”. En: Doctorado en Comunicación. Universidad Nacional de La Plata.

Cebrelli, A. y Arancibia, V. (2013). 'Representaciones nodales y narrativas nacionales. Las luchas por las significaciones de las representaciones nodales', clase $\mathrm{N}^{\circ} 9$ del curso Representaciones sociales $y$ comunicación, Maestría en Ciencias Sociales, Bs.As.: UNQ.

Cebrelli, A. y Arancibia, V. (2015). "Saberes descentrados y ecología de saberes. Una mirada decolonial sobre una carrera de comunicación (Ciencias de la comunicación de la Universidad Nacional de Salta)". En: Revcom Revista académica de la Red de carreras de comunicación, $N^{o} 1$ en http://perio.unlp.edu.ar/ojs/index.php/revcom/article/view/2618.

Cebrelli, A. y Arancibia, V. (2016). 'De la invisibilidad al estigma: Identidades y representaciones de la diferencia socio-cultural en telediarios de aire del NOA y NEA'. Paper leído en el XIV Encuentro Nacional de carreras de comunicación, San Salvador de Jujuy: UNJu. 
Cebrelli, A. y Arancibia, V. (2017). "Hacia una epistemología fronteriza en / desde América Latina. Aportes para una teoría decolonial de la comunicación”. En: Torrico, E. y Eloina Castro L. (coord.) Comunicación y decolonialidad. Quito: Ciespal (en prensa).

Cebrelli, A. y M. G. Rodríguez (comp.) (2013) "El mapa de los susurros. Representaciones mediáticas de la desigualdad y de la diferencia". En: Revista Tram(p)as de la comunicación y la cultura, $\mathrm{N}^{\circ} 76 \mathrm{La}$ Plata: FPyCS - UNLP.

Chatterjee, P. (2008). La nación en tiempo heterogéneo. Buenos Aires: Siglo XXI-Clacso.

Didi-Huberman, G. (2014). Pueblos expuestos, pueblos fulgurantes. Buenos Aires: Manantial.

Gravano, A. (Comp.) (2005). Imaginarios sociales de la ciudad media. Emblemas, fragmentaciones y otredades urbanas. Tandil: Red de Editoriales Universitarias Nacionales REUN.

Gravano, A. (2010). "El derecho a la ciudad”. En: Página 12. Recuperado el día 26 de septiembre de 2010 de: http://www.pagina12.com.ar/diario/suplementos/cash/17-4862-2010-12-26.html

Hall, S. (2010). Sin garantías. Trayectorias y problemáticas en estudios culturales. Bogotá: Universidad Javeriana.

Hall, S. y Dugay, P. (2003). Cuestiones de identidad. Buenos Aires: Amorrortu.

Harvey, D. (2007). “El arte de la renta: la globalización y la mercantilización de la cultura”. En: Espacios del capital. Hacia una Geografía crítica. Madrid: Akal.

León, E., Meave, K. y Ramos, A. (2009) “Proyección territorial comunitaria en la Ciudad de México: El caso del Movimiento Urbano Popular”. En: Ciudades nº 9.

Lynch, K. (1959) La imagen de la ciudad. Buenos Aires: Editorial Infinito.

Mayol, P. (1999). "Primera parte. Habitar". En: De Certeau, M.; Giard, L. y Mayol, P. La invención de los cotidiano 2. Habitar, cocinar. México: Universidad Iberoamericana, Cap. 1 y 2.

Ortíz, R. (1998) Otro territorio. Ensayos sobre el mundo contemporáneo. Bogotá: Convenio Andrés Bello.

Reguillo, R. (2008). Políticas de (In)visibilidad. La construcción social de la diferencia. Argentina: FLACSO.

Rodríguez, M. G. (2008). “La pisada, la huella y el pie”. En: Rodríguez, M. G. y Alabarces, P. (comp.) Resistencias y mediaciones. Estudios sobre Cultura popular, Bs. As: Paidós. pp. 307- 330;

Rodríguez, M. G. (2011). "Palimpestos: mapas, territorios y representaciones mediáticas". En: Revista Reflexiones Marginales. Disponible en: http://v2.reflexionesmarginales.com/index.php/num10dossier-blog/213-palimpsestos-mapas-territorios-y-representaciones-mediaticas.

Saavedra, M. N. (2013). La construcción de las identidades en el barrio Gauchito Gil. Estrategias comunicacionales y representaciones sociales. Tesis (Licenciatura de la carrera de Ciencias de la Comunicación). Salta, Argentina, Facultad de Humanidades, Universidad Nacional de Salta; 
Saavedra, M. N. (2015a). "Procesos de conformación de las identidades en el barrio Gauchito Gil. La incidencia del territorio en relación a las cuestiones de frontera y al desarrollo de prácticas comunicacionales locales". En: Burgos, R. (Ed.) Comunicación popular y alternativa en contextos de frontera. Mapeo de actores y experiencias en sectores populares de Salta. Salta: Editorial Gráfica 29 de Mayo.

Saavedra, M. N. (2015b). "Identidad(es) y representaciones sociales en el barrio Gauchito Gil. Un caso de ocupación y apropiación territorial, en vinculación a los procesos de transformaciones urbanas en Salta”. En: Revista Cuadernos, FHyCS-UNJu, No 48, pp. 65-85.

Segura, R. (2015). Vivir afuera. Antropología de la experiencia urbana. San Martín: Universidad Nacional de San Martín. UNSAM. Edita.

Silva, A. (2006) Imaginarios urbanos. Colombia: Arango Editores; (2012) Álbum de familia. La imagen de nosotros mismos. Medellín: Universidad de Medellín.

Troncoso, C. A. (2013) "Política turística y patrimonial en la Ciudad de Salta - Argentina: Disonancias en la protección y usos del centro histórico". En: Revista Estudios y Perspectivas en Turismo. Vol. 22, N 6. Recuperado el día 25 del mes de marzo del año 2014 de: <http://www.scielo.org.ar/scielo.php?script=sci_arttext\&pid=S18517322013000600001\&lng=es\&nr $\mathrm{m}=\mathrm{iso}>$. ISSN 1851-1732.

Vasilachis de Gialdino, I. (2013). Pobres, pobreza, identidad y representaciones sociales. Buenos Aires: Gedisa. 